\title{
Population dynamics, growth and energetics of jellyfish Aurelia aurita in a shallow fjord
}

\author{
Niels Jørn Olesen ${ }^{1}$, Kristian Frandsen ${ }^{2}$, Hans Ulrik Riisgård ${ }^{2}$ \\ ${ }^{1}$ National Environmental Research Institute, Vejlsøvej 25, PO Box 314, DK-8600 Silkeborg, Denmark \\ ${ }^{2}$ Institute of Biology, University of Odense, Campusvej 55, DK-5230 Odense M, Denmark
}

\begin{abstract}
Seasonal abundance and growth of the scyphomedusa Aurelia aurita were studied during 1991 and 1992 in the inner part of a small shallow fjord, Kertinge Nor, Denmark. During both years, mass occurrence of $A$. aurita was observed, and a maximum value of $\mathrm{ca} 300 \mathrm{ind} . \mathrm{m}^{-3}$ was measured in April 1992. Growth was poor in the fjord and the maximum mean umbrella diameter of medusae was only $54 \pm 12 \mathrm{~mm}$ and $37 \pm 15 \mathrm{~mm}$ in 1991 and 1992 respectively. Growth, clearance, ingestion and respiration were measured at different prey concentrations in the laboratory, and an energy budget was established. Ephyrae ( $4 \mathrm{~mm}$ in diameter) were offered rotiferas (Brachionus plicatilis) in concentrations ranging from 7 to 13000 ind. $l^{-1}$ Clearance of ephyrae decreased 30 to $50 \%$ with increasing prey concentration, and a curved relationship between prey concentration and ingestion was found. A maximum specific growth rate of $0.2 \mathrm{~d}^{\prime}$ was measured in the laboratory at $400 \mathrm{~B}$. plicatilis $\mathrm{l}^{-1}$, corresponding to $60 \mu \mathrm{g} \mathrm{C}^{-1}$. In Kertinge Nor, the growth rate never exceeded $0.1 \mathrm{~d}^{-1}$ The average zooplankton concentration in Kertinge Nor was only $5 \mu \mathrm{g} \mathrm{Cl}^{-1}$ and it could therefore be concluded that A. aurita was food limited in the fjord.
\end{abstract}

KEY WORDS: Population dynamics - Growth Energetics Feeding Respiration A Aurelia aurita

\section{INTRODUCTION}

The common jellyfish Aurelia aurita is a neritic scyphomedusa with a worldwide distribution (Kramp 1961). Mass occurrence of this species has been reported from many parts of the world: Cuba (Krumbach 1925); Japan (Yasuda 1968); Sweden (Hernroth \& Groendahl 1983); Greece (Papathanassiou et al. 1987). When abundant, $A$. aurita may have a significant impact on the structure of coastal plankton communities by predation on zooplankton. In Kiel Bight, Möller (1980b) reported that $A$. aurita was a major predator and food competitor of larval fish. Secondary effects have been described by Lindahl \& Hernroth (1983) who suggested that blooms of dinoflagellates in Gullmar Fjord, Sweden, were caused by a reduced copepod grazing pressure after an intense predation by $A$. aurita on the copepods.

During favourable food conditions, Aurelia aurita rapidly increases its growth rate and thus its predation pressure, and recently Bămsted (1990) suggested that natural populations usually are food limited. Further, it has been suggested that $A$. aurita utilizes patches of prey (Bailey \& Batty 1983, Båmstedt 1990). However, only few data are available on the actual growth potential of $A$. aurita during optimal food conditions, and an energy budget for this species has not yet been established to our knowledge.

In the present study, we evaluate to what extent a natural population of Aurelia aurita may be food limited. This was done by measuring the food consumption needed to result in maximum growth in the laboratory and subsequently comparing this value with the food available in a shallow fjord where $A$. aurita is numerous. Further, we compare the zooplankton concentration in the shallow fjord with the prey concentration needed to support the actual observed growth rate of $A$. aurita in the field. Finally, an energy budget, based on measurements of ingestion, growth and respiration in the laboratory, is established. 


\section{MATERIALS AND METHODS}

Study area and sampling site. All sampling of Aurelia aurita was done in Kertinge Nor and Kerteminde Fjord, a shallow fjord located on the east coast of the island of Fyn, Denmark (Fig. 1). The inner part Kertinge Nor, covers an area of $5.8 \mathrm{~km}^{2}$ and has an average depth of $2 \mathrm{~m}$ and a maximum depth of $3 \mathrm{~m}$. Mean residence time of water is approximately $2 \mathrm{mo}$ Salinity varies between 14 and $22 \%$ and water temperature between about $2{ }^{\circ} \mathrm{C}$ (February) and $22^{\circ} \mathrm{C}$ (July). The outer located Kerteminde Fjord $\left(2.8 \mathrm{~km}^{2}\right)$ has a maximum depth of $8 \mathrm{~m}$ and a mean residence time of water of 1 to $2 \mathrm{wk}$. Variations in salinity and temperature are the same as those for Kertinge Nor.

Population dynamics. Medusae of Aurelia aurita were sampled approximately every $2 \mathrm{wk}$ from June to December 1991 and from February to September 1992 at 7 stations in Kertinge Nor and at 2 stations in Kerteminde Fjord (Fig. 1). Sampling was done using a $0.6 \mathrm{~m}$ diameter plankton net with a mesh size of $500 \mu \mathrm{m}$. The net was equipped with a $0.5 \mathrm{I}$ cod end and the medusae were sampled in the daytime by hauling the net at a fixed depth of $1 \mathrm{~m}$ below the water surface. During sampling, the speed of the boat was 2 to 3 knots, and the amount of water passing through the net was measured with a 'Hydrobios flowmeter'. The volume of water filtered ranged from 3 to $10 \mathrm{~m}^{3}$ at each sampling station depending on the density of medusae. Current measurements inside and outside the net demonstrated that there was no significant clogging or overflow from the frontal opening of the net. The abundance of medusae at each station was estimated as the number of individuals caught divided by the volume of water filtered.

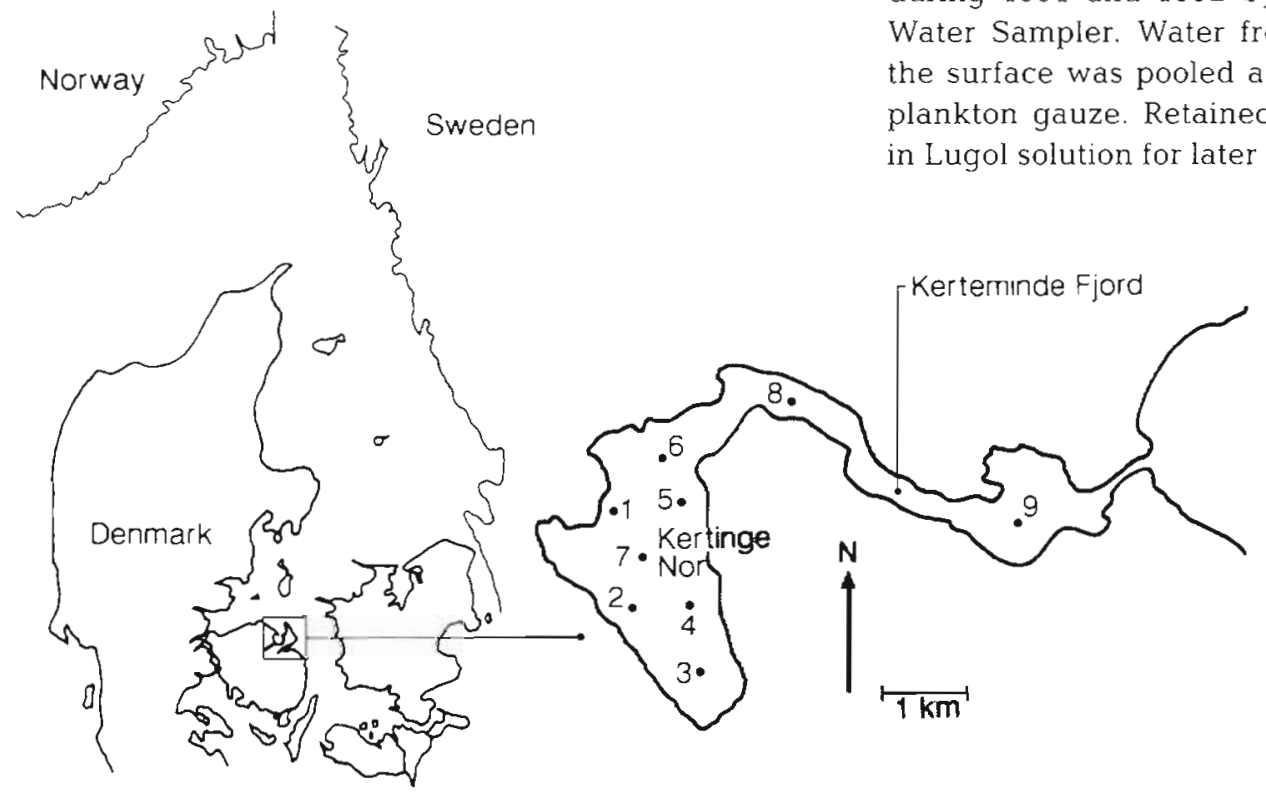

In order to measure the mean size of the population, live scyphomedusae caught in Kertinge Nor were measured within $2 \mathrm{~h}$ after sampling. Jellyfish were placed with the dorsal side down to flatten out the umbrella, and the interradial diameter was measured. The arithmetical means and standard deviations were calculated. The biomass of Aurelia aurita medusae in Kertinge Nor was estimated from the biometric relationships in medusae ranging in umbrella diameter $(D, \mathrm{~mm})$ from 10 to $50 \mathrm{~mm}$. Wet weight $\left(W_{\text {well }} \mathrm{mg}\right)$, dry weight $\left(W_{\text {dry }}=W, \mathrm{mg}\right)$, and ash-free dry weight ( $A F D W, \mathrm{mg})$ were determined as a function of bell diameter (Fig. 2) as described by Bamstedt (1990). The carbon content of the medusae was calculated from the dry weight carbon relation given by Schneider (1988): $1 \mathrm{mg}$ dry weight $=0.051 \mathrm{mg} \mathrm{C}$ for medusae $>2 \mathrm{~cm}$ and $0.071 \mathrm{mg} \mathrm{C}$ for medusae $<2 \mathrm{~cm}$.

The instantaneous specific growth rate $\left(\mu, \mathrm{d}^{-1}\right)$ of Aurelia aurita in Kertinge Nor was calculated from the formula:

$$
\mu=\left[\ln \left(\bar{W}_{t} / \bar{W}_{0}\right)\right] t^{-1}
$$

where $\bar{W}_{0}$ and $\bar{W}_{t}=$ mean body mass (dry wt) of medusae on Day 0 and Day $t$ respectively. From February to May when new ephyrae were produced continuously, $\mu$ was calculated from the dry weight of the largest medusa present on each sampling date. Medusae dry weights were calculated from the regression of umbrella diameter versus dry weight (Fig. 2) given by the equation:

$$
W=0.00173 D^{282}
$$

Water samples (9.9 l) for zooplankton analysis were collected every 2 wk on 2 stations in Kertinge Nor during 1991 and 1992 by using a 3.31 Heart Valve Water Sampler. Water from 0.5, 1 and $1.5 \mathrm{~m}$ below the surface was pooled and filtered through a $20 \mu \mathrm{m}$ plankton gauze. Retained organisms were preserved in Lugol solution for later analysis.

\footnotetext{
Fig. 1. Investigation area with sampling stations
} 


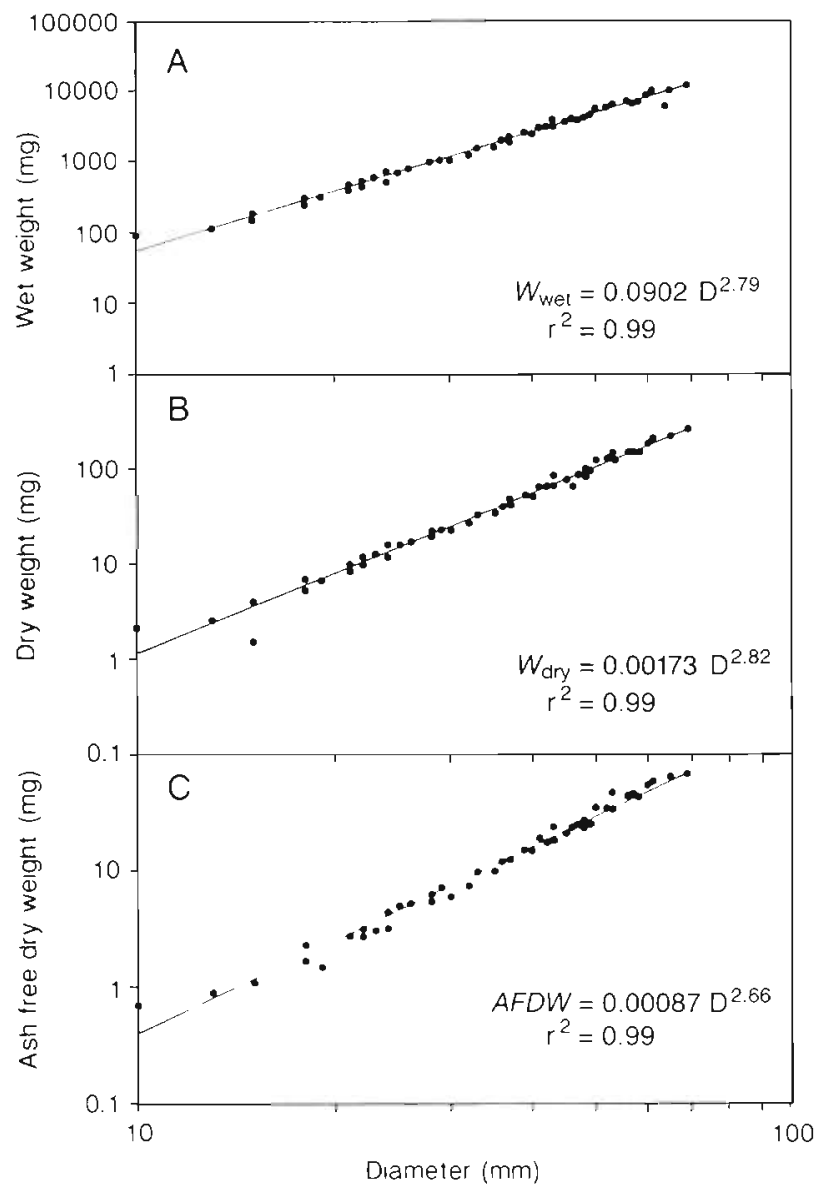

Fig. 2. Aurelia aurita. Relationships between body mass (wet weight, dry weight, ash-free dry weight) and umbrella diameter in jellyfish sampled 18 Jun 1991 in Kertinge Nor. No. of medusae examined $=52$

Laboratory experiments. Feeding and growth: Individuals of Aurelia aurita for experimental purposes were collected in Kertinge Nor, April 1992, using the same net as described above. The medusae were transported to the nearby Fjord Biology Laboratory, Kerteminde, and used in the experiments within $2 \mathrm{~h}$ after collection. Before the experiments were started the diameter of each individual was measured using a dissecting microscope. The medusae were then transferred to $5 \mathrm{l}$ plastic buckets with 4.61 filtered $(20 \mu \mathrm{m})$ seawater $(20 \%$ S) from the sampling site. The experiments were carried out in dim light at $15^{\circ} \mathrm{C}$ corresponding to the in situ temperature. Two separate series of experiments with different medusa size were carried out. In each experiment, rotifers (Brachionus plicatilis) were offered as prey. In Expt 1, the initial medusa size was approximately $4 \mathrm{~mm}$. Eight buckets were used with 10 pre-measured medusae in each bucket. The concentration of rotifers varied from bucket to bucket (from 130 to 13000 ind. $1^{-1}$ ) and the incubation period was $10 \mathrm{~d}$. In Expt 2, the initial medusa size was approximately $10 \mathrm{~mm}$. Four buckets were used with 10 pre-measured medusae in each bucket. The concentration of rotifers varied from 7 to 60 ind. $1^{-1}$ in the buckets and the incubation period was $7 \mathrm{~d}$. In both experiments, the water was changed daily; the medusae were carefully transferred to new seawater with new prey organisms in the same initial number as the day before, while the water in the previously occupied bucket was filtered through a $20 \mu \mathrm{m}$ plankton gauze. The retained prey organisms were preserved in Lugol solution and later counted by using a dissecting microscope.

Mean prey concentrations $(C)$, ingestion rate $(I)$ and clearance $(=$ volume of water cleared for prey organisms per time unit, $F$ ) were calculated according to the following equations:

$$
\begin{gathered}
C=\exp \left[\ln \left(C_{0} \times C_{t}\right) / 2\right], \\
I=\left(C_{t}-C_{0}\right) /(\mathrm{n} \times t), \\
F=V /(t \times \mathrm{n}) \ln \left(C_{0} / C_{t}\right)
\end{gathered}
$$

where $C_{0}$ and $C_{t}=$ no. of prey organisms at the start and end of each $24 \mathrm{~h}$ incubation period respectively; $\mathrm{n}=$ no. of medusae; $t=$ incubation period; and $V=$ volume of water. Three buckets without medusae and with prey concentrations of 500, 2000 and 8000 ind. $1^{-1}$, respectively, served as controls. In these buckets the number of prey organisms was unchanged after $24 \mathrm{~h}$ of incubation.

In Expt 1, the diameter of each individual was measured on Days $0,3,7 \& 10$ while the diameter was measured on Days $0 \& 7$ in Expt 2. At each prey concentration, $\mu$ was calculated by using Eq. (1), and the minimum prey concentration which resulted in maximum specific growth rate $\left(\mu_{\max }\right)$ was thus identified.

Respiration measurements: Respiration was measured in medusae on the last day (= Day $t$ ) of Expts 1 $\& 2$. The medusae (in groups of 5 to 10 individuals from each prey concentration) were transferred to a temperature controlled $\left(14.6 \pm 0.1^{\circ} \mathrm{C}\right)$ respiration chamber (volume $=10.1 \pm 0.1 \mathrm{ml}$ ) where an oxygen electrode (Radiometer, E 5046) measured the oxygen tension. The experimental set up used for the respiration measurements was identical to that used by Riisgård et al. (1980, Fig. 1) except that no magnetic stirrer was used to avoid possible damage on the fragile medusa. Instead, the medusae themselves mixed the water by their swimming activity. During each respiration measurement of maximal $2 \mathrm{~h}$ duration the decreasing oxygen saturation was continuously monitored (as a near straight line on a recorder) and the oxygen saturation was never allowed to fall below $60 \%$. Immediately after recording, 0 and $100 \%$ oxygen saturations were applied to 
the electrode to ensure that no change in calibration had taken place during the period of respiration recording. The respiration rate $\left(R_{t}\right)$ was calculated by using the expression:

$$
R_{t}=\Delta \mathrm{P} \alpha V / \Delta t,
$$

where $\Delta \mathrm{P}=$ change in oxygen tension during the period $\Delta t_{i} V=$ volume of respiration chamber; and $\alpha=$ the Bansen coefficient (depending on temperature and salinity) $=1.815 \mu \mathrm{mol} \mathrm{l}^{-1} \mathrm{~mm} \mathrm{Hg}^{-1}$ in the present work.

Additional experiments with different numbers of medusae and with freshly collected individuals were made to ensure that there was no effect of crowding or a change in respiration rate due to the long-term stay in the laboratory.

Bioenergetics: The energy balance of a medusa can be expressed by the following equation:

$$
I=P+R+E,
$$

where $I=$ ingestion; $P=$ production (growth); $R=$ respiration; and $E=$ excretion.

$P+R$ constitute assimilation $(A)$, and net growth efficiency $(N G E)$ is defined as the ratio $P / A$. In the present work, $P$ is expressed as body mass $\left(W_{\mathrm{dry}}\right)$ times $\mu$, and $R$ is expressed as the weight-specific respiration rate, $R / W_{\mathrm{dry}}=R_{m}\left(\mathrm{~J} \mathrm{~d}^{-1} \mathrm{mg}^{-1}\right)$. If the body mass of Aurelia aurita is expressed in energy equivalents, NGE can be calculated from the equation:

$$
N G E=\mu /\left(\mu+R_{m}\right)
$$

The following conversion factors were used in the present work: $1 \mathrm{mg}$ dry wt medusa $=3.5 \mathrm{~J}$ (Schneider 1988); $1 \mu \mathrm{mol} \mathrm{O}_{2}=0.448 \mathrm{~J} ; 1$ Brachionus plicatilis = $0.15 \mu \mathrm{g} \mathrm{C}=6.7 \times 10^{-3} \mathrm{~J}$ (Szyper 1989); clearance $\left(F, \mathrm{ml} \mathrm{h}^{-1}\right.$ medusa $\left.^{-1}\right)$ as a function of umbrella diameter $(D, \mathrm{~mm}), F=\mathrm{e}^{0143 D+1.73}$ (Olesen unpubl.).

\section{RESULTS}

\section{Population dynamics}

The first ephyrae of the new generation of Aurelia aurita in Kertinge Nor and Kerteminde Fjord appeared in February (Fig. 3A, Table 1). During the following months the number increased remarkably in both 1991 and 1992, and A. aurita obtained a maximum density of ca 300 ind. $\mathrm{m}^{-3}$ in April 1992 (Fig. 3A). In 1991, the number of medusae decreased from June and throughout the rest of the season, while the density in 1992 decreased from late April. On all sampling dates, the density of medusae in Kertinge Nor (Stns 1 to 7 ) was higher than in Kerteminde Fjord (Stns 8 \& 9) (Table 1).

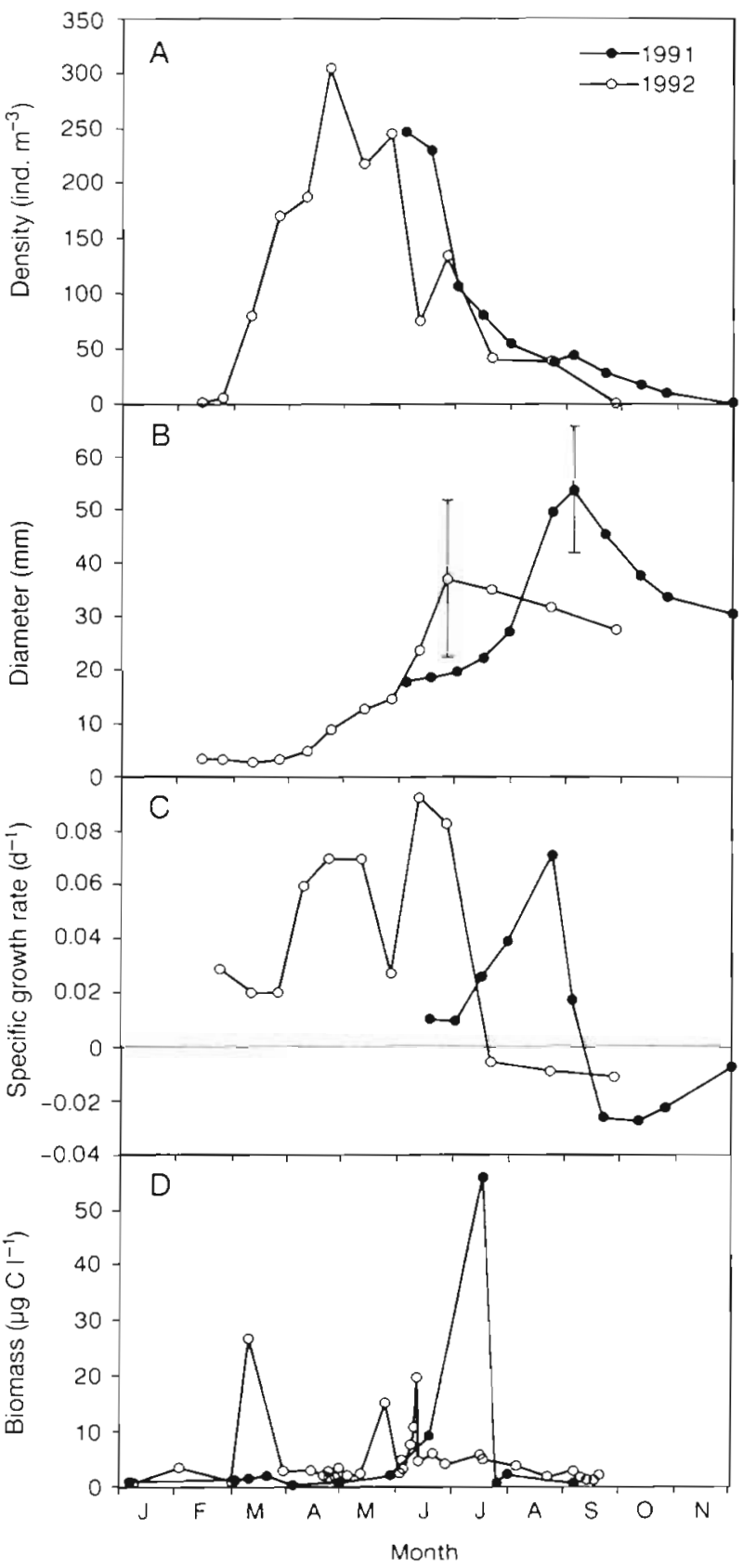

Fig. 3. (A) Aurelia aurita. Population density of jellyfish collected at Stns 1 to 7 in Kertinge Nor in 1991 and 1992. Mean population densities \pm SD and biomass of jellyfish in the whole fjord system are shown in Table 1. (B) Mean diameter of jellyfish at Stns 1 to 7 in 1991 and 1992. Representative $\mathrm{SD}$ is shown for 2 dates. (C) Instantaneous specific growth rate of jellyfish at Stns 1 to 7 in 1991 and 1992. (D) Biomass of zooplankton in Kertinge Nor 1991 and 1992

The growth pattern of Aurelia aurita in Kertinge Nor was different in 1991 compared with 1992 (Fig. 3B, C). During 1991, the growth rate was poor until early August, when a sudden increase in both diameter and specific growth rate was observed 
Table 1. Aurelia aurita. Mean population density $\pm \mathrm{SD}$ and biomass of jellyfish in Kertinge Nor (Stns 1 to 7 ) and Kerteminde Fjord (Stns 8 \& 9, see Fig. 1) in 1991 and 1992. The mean population density in Kertinge Nor in 1991 and 1992 is shown in Fig. 3

\begin{tabular}{|c|c|c|c|c|}
\hline \multirow[t]{2}{*}{ Date } & \multicolumn{3}{|c|}{$\begin{array}{c}\text { Density } \\
\text { (ind. } \mathrm{m}^{-3} \text { ) }\end{array}$} & \multirow{2}{*}{$\begin{array}{l}\text { Biomass } \\
\left(\mu \mathrm{g} \mathrm{Cl}^{-1}\right) \\
\text { Stns } 1 \text { to } 7\end{array}$} \\
\hline & Stns 1 to 7 & $\operatorname{Stn} 8$ & $\operatorname{Stn} 9$ & \\
\hline \multicolumn{5}{|c|}{1991} \\
\hline 3 Jun & $248 \pm 292$ & - & - & 170.0 \\
\hline 17 Jun & $231 \pm 136$ & 14 & 8 & 171.2 \\
\hline $1 \mathrm{Jul}$ & $107 \pm 127$ & 6 & 0 & 93.4 \\
\hline $15 \mathrm{Jul}$ & $81 \pm 73$ & $<1$ & 0 & 74.3 \\
\hline $29 \mathrm{Jul}$ & $55 \pm 19$ & 7 & 0 & 71.2 \\
\hline 22 Aug & $38 \pm 27$ & $<1$ & 0 & 251.2 \\
\hline $2 \mathrm{Sep}$ & $45 \pm 26$ & 22 & 0 & 351.0 \\
\hline 19 Sep & $29 \pm 17$ & 0 & 0 & 133.4 \\
\hline 8 Oct & $19 \pm 16$ & 4 & $<1$ & 55.2 \\
\hline $22 \mathrm{Oct}$ & $10 \pm 12$ & $<1$ & $<1$ & 25.5 \\
\hline 27 Nov & $2 \pm 1$ & 0 & $<1$ & 2.3 \\
\hline \multicolumn{5}{|c|}{1992} \\
\hline 13 Feb & $1 \pm 0.3$ & $<1$ & 1 & $<0.01$ \\
\hline $24 \mathrm{Feb}$ & $5 \pm 4$ & 3 & 0 & $<0.01$ \\
\hline $11 \mathrm{Mar}$ & $79 \pm 29$ & 4 & 2 & 0.2 \\
\hline $26 \mathrm{Mar}$ & $169 \pm 104$ & 71 & 23 & 0.9 \\
\hline $10 \mathrm{Apr}$ & $186 \pm 87$ & 37 & 5 & 3.9 \\
\hline $23 \mathrm{Apr}$ & $304 \pm 129$ & 55 & 13 & 29.7 \\
\hline 11 May & $216 \pm 125$ & 2 & 2 & 67.6 \\
\hline 26 May & $245 \pm 251$ & 118 & 46 & 118.4 \\
\hline 10 Jun & $74 \pm 37$ & 30 & 2 & 109.5 \\
\hline 25 Jun & $134 \pm 110$ & 46 & $<1$ & 450.0 \\
\hline $19 \mathrm{Jul}$ & $41 \pm 21$ & 1 & 1 & 122.8 \\
\hline $20 \mathrm{Aug}$ & $39 \pm 22$ & 1 & 0 & 73.8 \\
\hline 24 Sep & $22 \pm 27$ & 1 & 0 & 24.2 \\
\hline
\end{tabular}

(Fig. 3B, C). A maximum in the umbrella diameter was observed in early September 1991 where a mean diameter of only $54 \mathrm{~mm}$ was measured (Fig. 3B). In late August 1991, $\mu$ reached a maximum of $0.07 \mathrm{~d}^{-1}$. In 1992, a maximum of $\mu=0.09 \mathrm{~d}^{-1}$ was found in early June (Fig. 3C) with a maximum mean diameter of $37 \mathrm{~mm}$ in late June (Fig. 3B).

The following zooplankton groups were found in situ [mentioned in order of their contribution (\%) to the average total zooplankton biomass through 1991 and 1992]: Rotatoria (54.6) > Harpacticoida (16.2) > Chaetopoda (14.1) > Calanoida (3.6) > Gastropoda (3.2) > Lamellibranchia $(0.15)>$ Cirripedia (2.1) $>$ Cladocera (1.9) > Cyclopoida (1.3). Total biomass of zooplankton in Kertinge Nor is shown in Fig. 3D. During the $2 \mathrm{yr}$, the average zooplankton biomass was low with a mean value of $6.5 \mu \mathrm{g} \mathrm{Cl} \mathrm{l}^{-1}$ in 1991 and $4.7 \mu \mathrm{g} \mathrm{Cl}^{-1}$ in
1992. A close relationship between zooplankton biomass and growth of Aurelia aurita was observed (compare Fig. 3B, C, D). The maximum in zooplankton biomass in July 1991 (Fig. 3D) was followed by an increased growth of $A$. aurita (Fig. 3B, C). Similarly, a minor increase in zooplankton biomass during May 1992 resulted in increased growth rates of the jellyfish (Fig. 3C).

Data from gut content analysis are shown in Table 2. Although only a small number of medusae were examined, it is evident that rotifers made up a major part of Aurelia aurita's food on 11 March 1992 and 10 June 1992.

The biomass of Aurelia aurita in Kertinge Nor obtained a maximum of 350 and $450 \mu \mathrm{g} \mathrm{Cl}^{-1}$ in September 1991 and June 1992 respectively (Table 1). The carbon biomass of $A$. aurita exceeded that of the zooplankton in Kertinge Nor during most of the year, in some periods even by several orders of magnitude (compare Fig. 3D, Table 1).

\section{Laboratory experiments}

Feeding and growth

Small medusae $\left(D_{0}=4 \mathrm{~mm}\right)$ showed rapid growth when rotifers were offered in the concentration range 130 to 13000 ind. $\mathrm{I}^{-1}$ (Fig. 4A, Table 3). During the $10 \mathrm{~d}$ incubation period, the umbrella diameter increased from approximately 4 to $9 \mathrm{~mm}$ at the highest prey concentrations, corresponding to an increase in dry weight from 0.1 to $0.9 \mathrm{mg}$ (Table 3). The weight increase was slightly lower with lower concentrations of prey organisms. Medusae with an initial diameter

Table 2. Aurelia aurita. Average number of prey items $\pm \mathrm{SD}$ in gut content of medusae from Kertinge Nor, sampled in 1992 during daytime, and on 16 October 1991 at various times during a $24 \mathrm{~h}$ period. n: no. of medusae examined. $\bar{D}$ : mean diameter $\pm \mathrm{SD}$ of medusae

\begin{tabular}{|c|c|c|c|c|c|c|c|}
\hline Date & Rotifer & $\begin{array}{l}\text { Tintin- } \\
\text { nids }\end{array}$ & $\begin{array}{c}\text { Gastropoda } \\
\text { larvae }\end{array}$ & $\begin{array}{l}\text { Harpac- } \\
\text { ticoida }\end{array}$ & $\begin{array}{c}\text { Polychaeta } \\
\text { larvae }\end{array}$ & $\begin{array}{c}\bar{D} \\
(\mathrm{~mm})\end{array}$ & $\mathrm{n}$ \\
\hline \multicolumn{8}{|c|}{1991} \\
\hline \multicolumn{8}{|l|}{$16 \mathrm{Oct}$} \\
\hline 08:00 h & - & - & - & $5.8 \pm 4$ & - & $34 \pm 12$ & 10 \\
\hline $13: 30 \mathrm{~h}$ & - & - & - & $<1$ & - & $30 \pm 11$ & 25 \\
\hline $16: 45 \mathrm{~h}$ & - & - & - & $3.3 \pm 2$ & - & $28 \pm 10$ & 10 \\
\hline $21: 45$ & - & - & - & $2.6 \pm 3$ & - & $31 \pm 13$ & 10 \\
\hline \multicolumn{8}{|c|}{1992} \\
\hline $11 \mathrm{Mar}$ & $14 \pm 1$ & $1 \pm 2$ & 0 & 0 & 0 & $2.5 \pm 0.6$ & 17 \\
\hline $3 \mathrm{Apr}$ & $1 \pm 1$ & $11 \pm 5$ & $2 \pm 2$ & $<1$ & 0 & $3.5 \pm 0.8$ & 6 \\
\hline 11 May & $2 \pm 4$ & $2 \pm 2$ & $1 \pm 1$ & $<1$ & $<1$ & $13.2 \pm 4$ & 9 \\
\hline $10 \mathrm{Jun}$ & $8 \pm 7$ & $1 \pm 1$ & $4 \pm 3$ & $1 \pm 2$ & 0 & $17.9 \pm 5$ & 8 \\
\hline $19 \mathrm{Jul}$ & $<1$ & $<1$ & $1 \pm 1$ & $3 \pm 2$ & $<1$ & $29.2 \pm 1$ & 5 \\
\hline
\end{tabular}


Table 3. Aurelia aurita. Prey organism (Branchionus plicatilis) concentrations $(C)$ in growth experiments of $t$ days duration with 2 size groups of jellyfish with initial umbrella diameter $\left(D_{0}=4\right.$ or $\left.10 \mathrm{~mm}\right)$, intial body dry weight $\left(\bar{W}_{0}\right)$, and final size $D_{i}$ and $\bar{W}_{t}$ on Day $t$; all values are mean $\pm \mathrm{SD} ; \mu$; instantaneous specific growth rate, $\left[\ln \left(\bar{W}_{0} / \bar{W}_{t}\right) t^{-1} ; R_{t}\right.$ : individual respiration rate measured on Day $t ; R_{m}$ : weight-specific respiration rate, $R_{t} / \bar{W}_{i} ; N G E$ : net growth efficiency $=\mu /\left(\mu+R_{m}\right)$

\begin{tabular}{|c|c|c|c|c|c|c|c|c|c|}
\hline $\begin{array}{c}C \\
\left.(\text { ind. })^{-1}\right)\end{array}$ & $\stackrel{t}{\text { (d) }}$ & $\begin{array}{c}\bar{D}_{0} \\
\{\mathrm{~mm}\}\end{array}$ & $\begin{array}{c}\bar{D}_{t} \\
(\mathrm{~mm})\end{array}$ & $\begin{array}{l}\bar{W}_{0} \\
(\mathrm{mg})\end{array}$ & $\begin{array}{c}\bar{W}_{t} \\
(\mathrm{mg})\end{array}$ & $\begin{array}{c}\mu \\
\left(d^{-1}\right)\end{array}$ & $\begin{array}{c}R_{t} \\
\left(\mu \mathrm{mol} \mathrm{O} \mathrm{d}^{-1}\right. \\
\text { medusa })\end{array}$ & $\begin{array}{c}R_{\mathrm{m}} \\
\left(\mathrm{J} \mathrm{d}^{-1} \mathrm{mg}^{-1}\right)\end{array}$ & $\begin{array}{c}N G E \\
(\%)\end{array}$ \\
\hline \multicolumn{10}{|l|}{$D_{0}=4 \mathrm{~mm}$} \\
\hline $12940 \pm 1210$ & 10 & $4.3 \pm 0.86$ & $9.2 \pm 1.07$ & $0.12 \pm 0.06$ & $0.93 \pm 0.27$ & 0.20 & 2.90 & 1.40 & 33 \\
\hline $6166 \pm 937$ & 10 & $3.8 \pm 0.81$ & $9.1 \pm 1.78$ & $0.08 \pm 0.05$ & $0.98 \pm 0.57$ & 0.25 & 3.12 & 1.43 & 38 \\
\hline $2915 \pm 403$ & 10 & $4.2 \pm 1.37$ & $9.3 \pm 2.05$ & $0.12 \pm 0.09$ & $1.05 \pm 0.56$ & 0.22 & 3.46 & 1.48 & 34 \\
\hline $1514 \pm 298$ & 10 & $3.8 \pm 1.16$ & $9 . \pm 1.45$ & $0.09 \pm 0.07$ & $0.92 \pm 0.39$ & 0.23 & 4.20 & 2.05 & 28 \\
\hline $682 \pm 127$ & 10 & $4.5 \pm 1.45$ & $8.9 \pm 1.79$ & $0.15 \pm 0.10$ & $0.90 \pm 0.49$ & 0.18 & 2.21 & 1.10 & 36 \\
\hline $341 \pm 60$ & 10 & $3.6 \pm 1.26$ & $8 \pm 1.71$ & $0.08 \pm 0.08$ & $0.68 \pm 0.42$ & 0.21 & 2.14 & 1.41 & 34 \\
\hline $160 \pm 28$ & 9 & $3.8 \pm 1.19$ & $7.5 \pm 0.90$ & $0.09 \pm 0.07$ & $0.53 \pm 0.18$ & 0.20 & & & \\
\hline $130 \pm 98$ & 10 & $3.6 \pm 1.37$ & $6.5 \pm 0.91$ & $0.09 \pm 0.08$ & $0.36 \pm 0.14$ & 0.14 & 1.25 & 1.56 & 24 \\
\hline \multicolumn{10}{|l|}{$D_{0}=10 \mathrm{~mm}$} \\
\hline $60 \pm 19$ & 7 & $10.1 \pm 1.07$ & $8.7 \pm 0.54$ & $1.22 \pm 0.35$ & $0.78 \pm 0.14$ & -0.06 & 1.90 & 1.09 & -24 \\
\hline $27 \pm 9$ & 7 & $10.6 \pm 1.41$ & $8.9 \pm 1.43$ & $1.41 \pm 0.52$ & $0.89 \pm 0.40$ & -0.07 & 1.75 & 0.88 & -39 \\
\hline $11 \pm 3$ & 7 & $10.1 \pm 1.29$ & $7.6 \pm 1.09$ & $1.22 \pm 0.42$ & $0.57 \pm 0.21$ & -0.11 & 1.54 & 1.21 & -47 \\
\hline $7 \pm 2$ & 7 & $10.2 \pm 1.02$ & $7.8 \pm 0.99$ & $1.25 \pm 0.36$ & $0.59 \pm 0.21$ & -0.11 & 1.58 & 1.20 & -47 \\
\hline
\end{tabular}

of $10 \mathrm{~mm}$ showed negative growth when the prey concentration was between 7 and 60 rotifers $1^{-1}$. The umbrella diameter decreased to approximately $8 \mathrm{~mm}$ during $7 \mathrm{~d}$, corresponding to a decrease in dry weight from 1.3 to $0.7 \mathrm{mg}$ (Table 3 ).

Fig. $4 B$ shows $\mu$ for medusae of both size classes $\left(D_{0}=\right.$ $4 \mathrm{~mm}$ or $10 \mathrm{~mm}$ ). A maximum growth rate of approximately $0.2 \mathrm{~d}^{-1}$ was obtained at a prey density of approximately 400 rotifers $1^{-1}$. The growth rate did not increase at higher prey densities (Fig. 4B). Clearance decreased 30 to $50 \%$ with increasing prey concentration and a curved relationship between prey concentration and ingestion rate was found (Fig. 4 C, D). Clearance was slightly higher at the low prey concentration in the last period of the experiment, probably due to increasing medusae size during the experiment. The guts of the medusae were completely filled up with prey organisms when the medusae were kept at high prey concentrations. Part of the captured rotifers were killed, but apparently rejected instead of being digested. The ingestion rates at high prey concentrations were therefore overestimated and not used in the energetic calculations.

The individual respiration rate $\left(R_{t}\right)$ and the weightspecific respiration rate $\left(R_{m}\right)$ of the medusae are presented in Table 3 . Because medusa respiration measurements were made on individuals exposed to different food regimes during the previous days, resulting in different specific growth rates, the present respiration rates may be considered to be true values for the total metabolic rate, including the costs of growth.

\section{Bioenergetics}

The lowest prey concentration $C_{\min }$ (400 prey ${ }^{-1}$ ) resulting in maximal growth (Fig. 4B) may also be assessed from the ingestion rate $(I)$ and clearance $(F)$ as: $C_{\min }=I / F . I$ was calculated from assimilation $(\mathrm{A})$ by using a suggested assimilation efficiency of $90 \%$ : $I=A / 0.9$. A was calculated from the maximal growth rate, $G_{\text {max }}$ and maximal respiration rate $R_{t, \max }$ :

$$
A=G_{\max }+R_{t_{1} \max }
$$

where $G_{\max }=\mu_{\max } \times W_{t, \max }$ and $R_{t, \max }$ and $W_{t, \max }$ are expressed in energy equivalents. $\mu_{\max }, W_{t, \max }$ and $R_{t, \max }$ were calculated as mean values from the 6 highest prey concentrations at time $t$ (the last day of experiment) (Table 3).

Using these equations the following values were obtained: $G_{\max }=\mu_{\max } \times W_{\mathrm{tmax}}=0.70 \mathrm{~J} \mathrm{~d}^{-1}$ medusa $^{-1}$, and $I=2.05 / 0.9=2.28 \mathrm{~J} \mathrm{~d}^{-1}$ medusa ${ }^{-1}$ equivalent to 340 Brachionus plicatilis $\mathrm{d}^{-1}$ medusa ${ }^{1}$ The clearance of a $9 \mathrm{~mm}$ medusa was found to be $F=0.51 \mathrm{l} \mathrm{d}^{-1}$ medusa ${ }^{-1}$. Then $C_{\text {min }}=I / F=340 / 0.51=667$ ind. $l^{-1}$. This value is reasonably close to the actual 400 ind. $1^{-1}$ found in the experiment (Fig. 4B). According to the values given above, a $24 \mathrm{~h}$ energy budget for a $9 \mathrm{~mm}$ diameter Aurelia aurita medusa fed on $B$. plicatilis and growing at maximal rate can be established:

$$
I(2.28 \mathrm{~J})=P(0.70 \mathrm{~J})+R(1.35 \mathrm{~J})+E(0.23 \mathrm{~J}) .
$$

Thus, at maximal growth rate, respiration constitutes about $66 \%$ of assinulation whereas production constitutes $34 \%$ and net growth efficiency is approximately $35 \%$. 

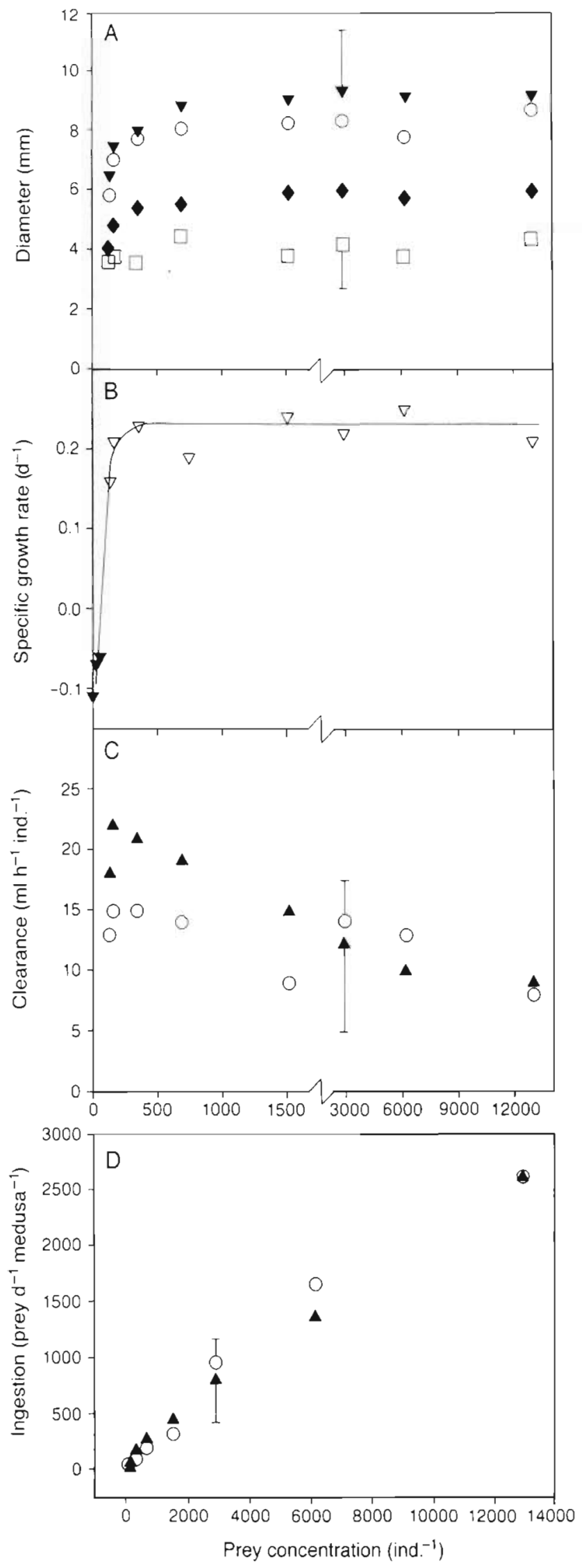

\section{DISCUSSION}

\section{Population dynamics}

The abundance of Aurelia aurita in Kertinge Nor was extremely high during 1991 and 1992. The average density was ca 220 ind. $\mathrm{m}^{-3}$ from late March to late May 1992 with a maximum density of approximately 300 ind. $\mathrm{m}^{-3}$ (Fig. 2A), which is almost 7 times higher than the maximum density reported in the literature: 10 ephyrae $\mathrm{m}^{-3}$ in Urazoko Bay, Japan (Yasuda 1968); 15 ephyrae $\mathrm{m}^{-3}$ in the Gullmar Fjord, Sweden (Hernroth \& Groendahl 1983) and 44 ephyrae $\mathrm{m}^{-3}$ in Elefsis Bay, Greece (Papathanassiou et al. 1987). The reason for the large number of medusae in Kertinge Nor is not clear, but the relatively protected fjord may support high densities of scyphistomae. Groendahl (1988) found evidence that scyphistomae of $A$. aurita are very rare outside protected fjords and lagoons. The abundance of scyphistomae on ceramic settling plates in the inner part of Kertinge Nor was estimated to be approximately $316000 \mathrm{~m}^{-2}$ in mid-September 1992, while the number was significantly lower in the outer fjord $\left(56000 \mathrm{~m}^{-2}\right)$ (pers. obs.). The higher density of scyphistomae and medusae (Table 1) in the inner part of the fjord, and the small individual size of medusae seem to indicate a local homogeneous population.

New ephyrae emerged from February to April in 1991 and 1992 (Fig. 3). A late winter, early spring liberation of ephyra has been described by many authors (Palmén 1945, Möller 1980a, Van der Veer 1985, Papathanassiou 1987). In contrast, Hernroth \& Groendahl (1985) reported that the main period of ephyrae release in the Gullmar Fjord, Sweden, was from October to November. Newly released ephyrae sank rapidly towards deeper water where they wintered in a diapause-like state before ascending towards the surface layers in April. We have no evidence of such a temporal linkage between release and appearance of ephyrae, but a new autumn generation seems unlikely in Kertinge Nor, as no ephyrae were found in the autumn in spite of well wind-mixed water.

Fig, 4. Aurelia aurita. Growth, clearance and ingestion by small medusae exposed to different prey concentration (Brachionus sp.). (A) Increase in umbrella diameter during a $10 \mathrm{~d}$ incubation period, initial size of medusae $=4 \mathrm{~mm}($ Expt 1$)$. Mean diameter of umbrella was measured ( $\square$ ) at time 0 , $(\bullet)$ after $83 \mathrm{~h},(\mathrm{O})$ after $177 \mathrm{~h}$, and ( $\mathbf{)}$ ) after $240 \mathrm{~h}$. (B) Instantaneous specific growth rate $(\nabla)$ initial diameter of medusae $D_{0}=4 \mathrm{~mm}$, final diameter $D_{t}=9 \mathrm{~mm}$, incubation period $=10 \mathrm{~d}$, (v) $D_{0}=10 \mathrm{~mm}, D_{t}=8 \mathrm{~mm}$, incubation period $=7 \mathrm{~d}$. Line drawn by eye. (C \& D) Daily measured clearance and ingestion rate during the $10 \mathrm{~d}$ incubation period. Representative SD is shown for single data set. Average clearance or ingestion based on: (O) time 0 to $113 \mathrm{~h},(\Delta) 113$ to $240 \mathrm{~h}$ 
The decreasing number of medusae during summer in Kertinge Nor (Fig. 3A) may be explained by outdrift of medusae to the open sea. In both years, a positive growth was observed in periods of decreasing numbers, and mortality due to food limitation seems therefore to be an unlikely explanation during those periods. Further, mortality in Aurelia aurita is usually low before maturation (Möller 1980a).

\section{Growth rates and energetics}

The growth of Aurelia aurita in 1991 and 1992 was very poor in Kertinge Nor (Fig. 3). The specific growth rate never exceeded $0.1 \mathrm{~d}^{-1}$, and the final umbrella diameter was only 54 and $37 \mathrm{~mm}$ in 1991 and 1992 respectively (Fig. 3B). These figures are considerably lower when compared to values obtained in similar studies. Thus, Möller (1980a) found a monthly increase of $41 \mathrm{~mm}$ in the diameter, corresponding to a specific growth rate of $0.18 \mathrm{~d}^{-1}$ in an A. aurita population in Kiel Bight (Germany), where the medusae obtained a maximum size of $197 \mathrm{~mm}$. The growth was even more pronounced in Gullmar Fjord, Sweden, where a specific growth rate of $0.23 \mathrm{~d}^{-1}$ was reported by Hernroth \& Groendahl (1983) and in the Western Wadden Sea, where a maximum specific growth rate of $0.2 \mathrm{~d}^{-1}$ was calculated from data of Van der Veer (1985)

In the laboratory experiment, the specific growth rate was determined only for jellyfish with initial sizes of 4 and $10 \mathrm{~mm}$, while the growth rate in Kertinge Nor was obtained for jellyfish of varying sizes (2 to $54 \mathrm{~mm}$ ). It is, however, valid to compare the maximal growth rate found in the laboratory $\left(0.22 \mathrm{~d}^{-1}\right)$ directly with the maximal growth rate of $0.09 \mathrm{~d}^{-1}$ estimated in Kertinge Nor (Fig. 3C), if the specific growth rate of Aurelia aurita is constant with body mass. A constant instantaneous growth rate at increasing body mass depends upon a linear relationship between body mass ( $W_{\text {dry }}$ ) and metabolic rate $(M)$, that is $b=1$ in the allometric relationship $M=a W_{\mathrm{dry}}{ }^{b}$ (see e.g. Jørgensen 1990). Larson (1987) measured respiration rate as a function of body mass in 10 different hydromedusae species and 2 scyphomedusae species, and found that most $b$-values were not significantly different from 1.0 , and recently Uye (Hiroshima University, pers. comm.) found a $b$-value $=1.0$, over a wide size range of $A$. aurita medusae. Thus, it may be assumed that laboratory growth data on $A$. aurita can be compared to growth data from Kertinge Nor, and therefore, it can be concluded that $A$. aurita does not utilize its growth potential in Kertinge Nor.

The maximal growth rate (of 4 to $9 \mathrm{~mm}$ medusae) in the laboratory was attained at a prey concentra- tion of approximately 400 Brachoionus plicatilis $\mathrm{1}^{-1}$ and above (Fig. 4B), which corresponds to $60 \mu \mathrm{g} \mathrm{C}$ $1^{-1}$ On the average, the carbon concentration of zooplankton in Kertinge Nor was only 6.5 and $4.7 \mu \mathrm{g} \mathrm{C}$ $\mathrm{I}^{-1}$ in 1991 and 1992 respectively (Fig, 3D), and the growth of 4 to $9 \mathrm{~mm}$ medusae in Kertinge Nor was therefore severely food limited. However, this conclusion can also be extended to other size medusae in Kertinge Nor by calculating the lowest prey concentration, different sized medusae need to attain maximal growth: using the respiration versus body mass relationship found for Aurelia aurita by Larson (1986), and assuming a NGE of $35 \%$ (Fraser 1969, this study), and an assimilation efficiency of 0.9 (Purcell 1983), the ingestion for a $20 \mathrm{~mm}$ medusae is found to be $2.1 \mathrm{~J} \mathrm{~d}^{-1}$ medusa ${ }^{-1}$ corresponding to 320 B. plicatilis $\mathrm{d}^{-1}$ medusa ${ }^{-1}$. Clearance of a $20 \mathrm{~mm}$ medusa feeding on $B$. plicatilis $=2364 \mathrm{ml} \mathrm{d}^{-1}$ medusa $^{-1}$ (Olesen unpubl.), and hence the prey concentration needed for maximal growth is $135 \mathrm{~B}$. plicatilis $\mathrm{l}^{-1}$ corresponding to $20 \mu \mathrm{g} \mathrm{Cl}^{-1}$. The value for

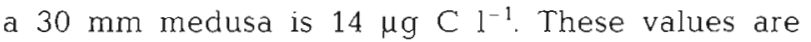
likely to be underestimated because the respiration rate used in the calculations was not obtained from jellyfish growing at maximal rate. In conclusion, there is little doubt that $A$. aurita is food limited most of the season in Kertinge Nor, and this explains the poor growth observed.

The maximum growth rate obtained in laboratory experiments (Fig. $4 \mathrm{~B}$ ) is close to the maximum growth rate observed in natural populations in other systems. In nature, however, this growth rate is generally only obtained for short periods, and food limitation of Aurelia aurita may therefore be prevalent in nature.

Fraser (1969) calculated a net growth efficiency of $37 \%$ in Aurelia aurita, which is close to the value of $35 \%$ obtained in this study. From the energy budget established in the present work it was calculated that respiration constituted about $66 \%$ of assimilation, and production constituted $34 \%$ of assimilation at a maximum growth rate. In Kertinge Nor, however, growth rate of $A$. aurita was less than $0.1 \mathrm{~d}^{-1}$ dunng 1991 and 1992 (Fig 3C), and NGE therefore never exceeded $24 \%$ (Table 3), indicating that the medusae at the low food conditions channelled more than $76 \%$ of the assimilated food energy into respiration and less than $24 \%$ into somatic growth. During 1982 when the abundance of medusae was high in the Kiel Bight, Schneider (1989) also found that $80 \%$ of the assimilated food energy was used for respiration while $18 \%$ was used for somatic growth. These figures were 61 and $35 \%$, respectively, at a significantly lower density of medusae and higher prey levels. 


\section{Food source}

Stoecker et al. (1987) demonstrated the capability of Aurelia aurita to feed on different sources of microzooplankton (20 to $200 \mu \mathrm{m}$ size fraction). The rotifer Brachionus plicatilis lies within this size range and was chosen as food item in the present growth experiments. The clearance of approximately $15 \mathrm{ml} \mathrm{h}^{-1}$ ephyra $^{-1}$ (Fig. 4C) may be compared to a study by Båmstedt (1990), who found a clearance value of approximately $1 \mathrm{ml} \mathrm{h}^{-1}$ ephyra ${ }^{-1}$, using ephyrae of $A$. aurita with a diameter of $5 \mathrm{~mm}$ and the rotifer Synchaeta sp. as prey (605 ind. $\mathrm{l}^{-1}$ ).

In the present laboratory experiments the ingestion rate leveled off as prey concentration increased, but saturation was not observed (Fig. 4D). Clearance remained high even at a prey concentration of 13000 ind. $\mathrm{l}^{-1}$. These results demonstrate a high 'grazing' potential of Aurelia aurita, even at extremely high zooplankton densities. In Kertinge Nor, peaks in zooplankton biomass were followed by a marked growth of $A$. aurita. Thus, a bloom of rotifers with a density of more than 19000 ind. $1^{-1}$ during July 1991 (Fig. 3D) was followed by increased growth of $A$. aurita after which the zooplankton density decreased, most likely due to an intense predation by the jellyfish. The 2 major peaks in zooplankton biomass during 1992 were also caused by blooms of rotifers and the gut content analysis showed a high number of rotifers in medusae collected during these 2 blooms (Table 2). These data demonstrate that rotifers are an important food source for $A$. aunita in Kertinge Nor.

Båmstedt (1990) calculated that average prey concentration characteristics for neritic environments could not explain the maximum growth rates observed in field populations of Aurelia aurita. He therefore suggested that exploitation of patches of prey might be important in the trophodynamics of $A$. aurita. It is known that $A$. aurita can alter its swimming patterns to facilitate efficient utilization of abundant prey (Baily \& Batty 1983), and recently Arai (1991) found experimental evidence for the ability of $A$. aurita to detect aggregations of zooplankton. The average zooplankton density in Kertinge Nor could not either support positive growth in the medusae. As a mean, the zooplankton biomass was approximately $5 \mu \mathrm{g} \mathrm{C} \mathrm{I}^{-1}$ in Kertinge Nor, corresponding to only 33 Brachionus plicatilis $\mathrm{l}^{-1}$. Positive growth was not observed at this prey concentration in the laboratory experiment (Table 3). Moreover, in 1991 the umbrella diameter of the $A$. aurita medusae continued to increase through August although the zooplankton biomass became extremely low in Kertinge Nor (Fig. 3B, D). Thus, $A$. aurita is apparently growing in excess of its food resources in Kertinge Nor.
The average biomass of ciliates in Kertinge Nor was $4 \mu \mathrm{g} \mathrm{C} \mathrm{l}^{-1}$ in 1991 and $12 \mu \mathrm{gC}^{-1}$ in 1992 (data not shown) and Stoecker et al. (1987) demonstrated the ability of Aurelia aurita to feed on large non-loricate ciliates. Ciliates might therefore contribute as food source for A aurita in Kertinge Nor where as phytoplankton is known to be of minor importance (Möller 1980b, Stoecker et al. 1987, Båmstedt 1990). The observed growth of medusae may also in part be explained by high production of rotifers. Secondary production of Synchaeta cecilia and S. triophthalma ranged from 1.3 to $8.7 \mu \mathrm{g} \mathrm{C} \mathrm{l}^{-1} \mathrm{~d}^{-1}$ and from 0.1 to $1.0 \mu \mathrm{g} \mathrm{C}^{-1} \mathrm{~d}^{-1}$, respectively, in the estuarine Pontomac River (Heinbokel et al. 1988). However, the most important factor might be undersampling of zooplankton in the present study. We believe that undersampling of zooplankton is due to dial vertical migration of epibenthic copepods (harpacticoids). Examination of stomach contents of medusae caught in Kertinge Nor, in the autumn 1991, gave evidence that harpacticoid species made up the major part of Aurelia aurita's food and the number of Harpacticoida found in the stomachs of medusae caught at night was slightly higher than the number present in medusae caught during day (Table 2). Moreover, the density of epibenthic copepods in the water column during night can exceed the density during day in Kertinge Nor by a factor of 20 (unpubl. results). Therefore, predation on Harpacticoida during night may in part explain observed growth rate of $A$. aurita in Kertinge Nor. So far, no work has addressed the problem of diurnal variations in predation by $A$. aurita, but it may be of great importance in understanding the trophodynamics of this species in certain shallow waters.

Acknowledgements. Peter Bondo Christensen is greatly acknowledged for a critical review of the manuscript. The study was partly supported by the Danish National Agency of Environmental Protection (Hav 90).

\section{LITERATURE CITED}

Arai, M. N. (1991). Attraction of Aurelia and Aequorea to prey. Hydrobiologia 216/217: 363-366

Bailey, K. M., Batty, S. R. (1983). A laboratory study of predation by Aurelia aurita on Larval Herring (Clupea harengus): experimental observations compared with model predictions. Mar. Biol. 72: 295-301

Båmstedt, U. (1990). Trophodynamics of the scyphomedusae Aurelia aurita. Predation rate in relation to abundance, size and type of prey. J. Plankton Res. 12: 215-229

Fraser, J. H. (1969). Experimental feeding of some medusae and chaetognatha. J. Fish. Res. Bd Can. 26: 1743-1762

Groendahl, F. (1988). A comparative ecological study on the scyphozoans Aurelia aurita, Cyanea capillata and C. lamarckii in the Gullmar Fjord, Western Sweden, 1982 to 1986. Mar. Biol. 97: 441-450 
Heinbokel, J. F., Coats, D. W., Henderson, K. W., Tyler, M. A (1988). Reproduction rates and secondary production of three species of the rotifer genus Synchaeta in the estuarine Pontomac River. J. Plankton Res. 10: 659-674

Hernroth, L., Groendahl, F. (1983). On the biology of Aurelia aurita (L.). 1. Release and growth of Aurelia aurita (L.) ephyrae in the Gullmar Fjord, Western sweden, 1982-1983. Ophelia 22: 189-199

Hernroth, L., Groendahl, F. (1985). On the biology of Aurelia aurita (L.). 2. Major factors regulating the occurrence of ephyrae and young medusae in the Gullmar Fjord, Western Sweden. Bull. mar. Sci. 37(2): 567-576

Jargensen, C. B. (1990). Bivalve filter feeding: hydrodynamics, bioenergetics, physiology and ecology. Olsen \& Olsen, Fredensborg

Kramp, P. L. (1961). Synopsis of the medusae of the world. J. mar. biol. Ass. U.K. 40: 1-469

Krumbach, T. (1925). Syphozoa. Handb. Zool. 1: 522-686

Larson, R. J. (1987). Respiration and carbon turnover rates of medusae from the NE Pacific. Comp. Biochem. Physiol. $87 \mathrm{~A} 1$ : $93-100$

Lindahl, O., Hernroth, L. (1983). Phyto-zooplankton community in coastal waters of Western Sweden - an ecosystem off balance? Mar. Ecol. Prog. Ser. 10: 119-126

Möller, H. (1980a). Population dynamics of Aurelia aurita medusae in Kiel Bight, Germany (FRG). Mar. Biol. 60 $123-128$

Möller, H. (1980b). Scyphomedusae as predators and food competitors of larval fish. Meeresforsch. 28: 90-100

Palmén, E. (1954). Seasonal occurrence of ephyrae and subsequent instars of Aurelia aurita (L.) in the shallow waters of Tvarminne, S. Finland. Arch. Soc. Vanamo 8: 122-131

This article was submitted to the editor
Papathanassiou, E., Panayotidis, P., Anagnostaki, K. (1987). Notes on the biology and ecology of the jellyfish Aurelia aurita L. in Elefis Bay (Saronikos Gulf, Greece). Mar. Biol. 8: $49-58$

Purcell, J. E. (1983). Digestion rates and assimilation efficiencies of siphonophores fed zooplankton prey. Mar. Biol. 73 : $257-261$

Riisgård, H. U., Randløv, A., Kristensen, P. A. (1980). Rates of water processing, oxygen consumption and efficiency of particle retention in veligers and young post-metamorphic Mytilus edulis. Ophelia 19: 37-47

Schneider, G. (1988). Chemische Zusammensetzung und Biomasseparameter der Ohrenqualle Aurelia aurita. Helgoländer Meeresunters. 42: 319-327

Schneider, G. (1989). Estimation of food demands of Aurelia aurita medusae populations in the Kiel Bight/Western Baltic. Ophelia 31(1): 17-27

Stoecker, D., Michaels, A. E., Davies, L. H. (1987). Grazing by the jellyfish. Aurelia aurita, on microzooplankton. J. Plankton Res. 9: 901-915

Szyper, J. P. (1989). Nutritional depletion of the aquaculture feed organisms Euterpina acutifrons, Artemiá sp. and Brachionus plicatilis during starvation. J. Wrld Aquat. Soc. 20: $162-169$

Van der Veer, H. W., Oorthuysen, W. (1985). Abundance, growth and food demand of the scyphomedusa Aurelia aurita in the Western Wadden Sea. Neth. J. Sea. Res. 19(1): $38-44$

Yasuda, T. (1968). Ecological studies on the jellyfish Aurelia aurita in Urazoko Bay, Fukui Prefecture. 2. Occurrence pattern of the ephyrae. Bull. Jap. Soc. Sci. Fish. 34: 983-987

Manuscript first received: March 14, 1993

Revised version accepted: December 6, 1993 